\title{
PERCEPÇÕES DOS CURSISTAS SOBRE A ATUAÇÃO DO TUTOR: UM ESTUDO DE CASO EM EAD
}

\author{
VIÇOSA/MG MAIO/2018 \\ Érica Aparecida Coelho - UFV - erica.coelho@ufv.br \\ Silvane Guimarães Silva Gomes ～- UFV - silvane@ufv.br \\ Thalita Rodrigues Rossi - UFV - thalita.rossi@ufv.br \\ Tereza Angélica Bartolomeu - UFV - angelica@ufv.br \\ Wellington Adilson Domingos Júnior - UFV - wellington.domingos@ufv.br \\ Tipo: Relato de Experiência Inovadora (EI) \\ Categoria: Métodos e Tecnologias \\ Setor Educacional: EDUCAÇÃO CONTINUADA EM GERAL
}

\begin{abstract}
RESUMO
O presente artigo objetiva averiguar a percepção dos cursistas de um curso a distância de capacitação de tutores sobre a atuação do tutor. Estudos sobre uso das tecnologias educacionais vêm sendo abordados sob diferentes perspectivas, as quais envolvem o papel desempenhado pelos alunos, pelos professores e pelos tutores, bem como as metodologias adotadas. Conclui-se que a atuação do tutor de forma mais ativa é vista de forma positiva pelos cursistas bem como, interfere no processo de ensino-aprendizagem e na permanência dos cursistas.
\end{abstract}

Palavras-chave: Tutor; Cursista; EAD 


\section{Introdução}

A Educação a distância na atualidade é uma forma viável de oportunidade educacional para um grande número de pessoas. É uma opção para o cidadão do século XXI na formação das novas gerações, transmitindo conhecimento científico e cultural, além de trazer "em si os limites e as contradições da sociedade moderna e também a possibilidade de inclusão social”. (MELLO et.al., 2017, p.28).

A crescente disponibilidade de banda larga de internet e as tecnologias de informação e comunicação (TICs) imersas no cotidiano das pessoas têm facilitado a comunicação, a pesquisa e consequentemente a ampliação da oferta de cursos a distância nas mais diferentes áreas do conhecimento. Esse "fenômeno" das TICs é caracterizado por Castells (2010) como a "Era da Informação e Comunicação" cujas transformações sociais e culturais se dão com a emergência da cibercultura.

Nesse contexto, a Educação a Distância vem assumindo, de forma crescente, destaque no cenário educacional contemporâneo. Trata-se de uma modalidade de ensino que possibilita uma maior autonomia do estudante, passando esse a ser o responsável pelo controle, planejamento e gerenciamento do tempo a ser dedicado ao estudo e ao desenvolvimento do próprio aprendizado. O'Rourke (2003), salienta que as pessoas que procuram pela educação à distância, normalmente, são adultos que possuem uma vida ativa com compromissos familiares e profissionais, portanto, têm objetivos bem definidos e, frequentemente, relacionados aos benefícios que a aprendizagem pode proporcionar na sua vida e no trabalho. Além disso, "podem estar afastado do ensino formal há algum tempo" e "não ter possibilidade de contatar bibliotecas ou outros recursos acadêmicos" (O'ROURKE, 2003, p.22).

Quando se trata de educação a distância uma importante figura no processo de ensinoaprendizagem é o tutor. Esse assume a função de criar meios para estimular a participação dos alunos, acompanhar o processo de aprendizagem, tornando-se um elo entre aluno e professor, como mediador, motivador, estabelecendo uma relação de empatia com os alunos para o desenvolvimento das atividades, visando o êxito na finalização do curso. Além disso, cabe ao tutor o processo de interação ao longo do curso também no sentido de informar sobre as datas e atividades a serem realizadas, esclarecer dúvidas, ajudar a superar dificuldades, corrigir e disponibilizar feedbacks sobre as atividades, entre outros.

Nesse contexto, o presente estudo, tem o objetivo geral de averiguar a percepção de cursistas sobre a importância do tutor no desenvolvimento de um curso a distância de 
capacitação de tutores.

\section{Fundamentação teórica}

Estudos sobre o uso das tecnologias educacionais vêm sendo abordados sob diferentes perspectivas, as quais envolvem o papel desempenhado pelos alunos, pelos professores e pelos tutores, bem como as metodologias adotadas. Nesse sentido, o ensino a distância vem passando por muitas transformações, se aprimorando, conquistando seu espaço e valor, uma vez que as inovações tecnológicas surgem a todo momento, caracterizando-se como novas possibilidades para o processo de ensinoaprendizagem.

Utilizar tecnologias de informação e comunicação (TICs) no processo de ensinoaprendizagem apresenta-se como boa alternativa e potencial solução para a formação continuada, sem a necessidade de deslocamento. Para Martins (2002), as TICs facilitam o alcance do conhecimento e do saber em diferentes áreas do conhecimento, permitindo a exploração de informações em tempo real. Além disso, permite uma forma de aprendizado mais ampla, uma vez que vai possibilitar trabalhar em grupo, comunicar-se via Internet e desenvolver a capacidade de localizar, sintetizar e divulgar informações.

Segundo Silva e Teixeira da Silva (2009, p. 76), "Na abordagem tradicional, o aluno é um ser passivo, que recebe os conteúdos já devidamente trabalhados pelo professor", não se espera reflexão, criticidade, troca de conhecimentos, o aluno "estuda para obter nota e ser aprovado no fim do ano" ou curso. O não acompanhamento pelo professor do dinamismo que caracteriza a "sociedade da informação" provoca um distanciamento do estudante, correndo-se o risco, inclusive, de criar um círculo vicioso de desmotivação e baixo aproveitamento no ensino (TORI, 2002). Paulo Freire (1974) conceitua essa forma de educar como Educação Bancária, sendo essa "a imposição do conhecimento realizada pelo professor sobre o aluno. O primeiro faz a exposição de conteúdos e o segundo permanece em uma passiva atitude de mero recebimento desses conteúdos".

$\mathrm{Na}$ EAD o foco principal é o estudante, o aprendizado tende a ser mais efetivo, especialmente se o estudante é estimulado a ter um comportamento mais ativo. Este processo se dá pela reorganização de todo o processo de ensino que afeta diretamente o ensinar e aprender (BELLONI, 2001). Desse modo, as TICs, por estarem abrindo novas possibilidades para o ensino-aprendizagem, enquadram-se bem neste contexto, uma vez que evidenciam a possibilidade de interação, de comunicação, de acesso à informação, e converte-se em um meio interativo e ativo. Ainda nesse contexto, Moran (2012), defende que as práticas de ensino sejam presenciais ou a distância ou de forma 
híbrida devem ser mais inovadoras, especialmente com uso de tecnologias digitais que são acessíveis, instantâneas e podem ser utilizadas de diferentes formatos em qualquer tempo e lugar.

Os estudantes podem sentir dificuldades em tornarem-se ativos no processo de aprendizagem, enquanto os professores podem ter dificuldades em atuar como tutores, não desempenhando bem as funções de facilitador das discussões, administrador dos grupos tutoriais, desafiador do pensamento crítico dos estudantes, bem como, avaliador da aprendizagem dos estudantes. Diante disso, cabe ao tutor desempenhar essa função, servindo de elo permanente entre estudante e professor, e atuando com o professor no acompanhamento dos estudantes.

Para Martins (2003), o tutor deve despertar no estudante o desejo de aprender. A autora acrescenta que,

A orientação tutorial é compreendida assim como um dos elementos do processo educativo que propicia a ruptura da noção tempo/espaço da escola tradicional, uma vez que o processo dialógico que se estabelece entre o aluno e o tutor deve ser único e exclusivo onde o entorno, o percurso, as expectativas, as dificuldades etc. constituem elementos dinamizadores desse processo (MARTINS, 2003, p. 8).Para desempenhar essa tarefa, o tutor deve estar preparado para servir de facilitador e mediador, apoiando, acompanhando e traçando estratégias que motivem e envolvam o estudante em todo 0 processo de aprendizagem. Além disso, o tutor desse estar apto a responder as dúvidas e questionamentos sobre o conteúdo do curso ou em relação as TICs utilizadas, estimular debates e discussões, apresentar feedback das atividades realizadas, buscando sempre fazer com que o estudante se sinta amparado e objetivando desenvolver as competências necessárias para a compreensão, assimilação e aplicação do conteúdo estudado (GOMES; VILLANI, s.d., p. 9). Por fim, todas as funções desempenhadas pelo tutor devem objetivar estimular o estudante a refletir sobre determinado tema, de forma a despertar o pensamento crítico e uma aprendizagem significativa.

Assim sendo, algumas características são fundamentais para o exercício da tutoria: cordialidade, que está associada a deixar o cursista confortável; a aceitação relacionada à compreensão de sua realidade; honradez, que diz respeito à honestidade permanente na relação com o cursista; a empatia, relacionada ao estreitamento dos laços. Todas essas qualidades apontam "a relevância do afeto como um componente importante no exercício da tutoria a distância, visto que nessa modalidade, o cursista muitas vezes se sente sozinho e as taxas de evasão são relativamente altas" (ARETIO, 2001 
apud TELLES; ESQUINCALHA, 2017, p.14).

\section{METODOLOGIA}

Este estudo deriva-se da experiência vivenciada no curso de Capacitação de Tutores para EAD oferecido por uma Instituição de Ensino Superior - IES. Trata-se de um estudo de metodologia mista que apresenta aspectos qualitativos e quantitativos, que de acordo com Minayo e Sanches (1993, p. 247), podem "agir como metodologias complementares". Devido à natureza do estudo optou-se pelo estudo de caso que, segundo Latorre et al., (2003) apud Meirinhos e Osório (2010, p.52) "rege-se dentro da lógica que guia as sucessivas etapas de recolha, análise e interpretação da informação dos métodos qualitativos, com a particularidade de que o propósito da investigação é o estudo intensivo de um ou poucos casos".

A população do estudo foi 375 (trezentos e setenta e cinco) alunos que participaram do curso entre os anos de 2015 e primeiro semestre de 2018. O perfil da população estudada foi extraído de um questionário que versava sobre idade, sexo e grau de escolaridade. As informações relacionadas à percepção dos cursistas quanto a importância do tutor no processo de ensino aprendizagem, foram coletadas também através do questionário estruturado on-line disponibilizado no ambiente virtual de aprendizagem (AVA) próprio da instituição. A análise dos dados foi realizada através do software Microsoft Excel 2013.

\section{Resultados e discussão}

Após a análise dos dados tem-se que $65 \%$ (242) dos cursistas eram do sexo feminino e $35 \%$ (133) eram do sexo masculino. Tratando-se da idade dos cursistas $15 \%$ (57) tinham de 18 a 25 anos, 49\% (183) de 26 a 35 anos, 30\% (113) de 36 a 50 anos, 6\% (22) acima de 50 anos. Sobre o grau de escolaridade, todos os cursistas possuíam ensino superior completo ou em andamento.

Quanto a percepção dos cursistas em relação à importância do tutor no desenvolvimento do curso, procurou-se identificar como o suporte dos tutores contribuíram para o aprendizado dos cursistas como representado na figura 1:

Figura 1: Contribuição do suporte dos tutores no aprendizado dos cursistas, 2015 a 2018. 


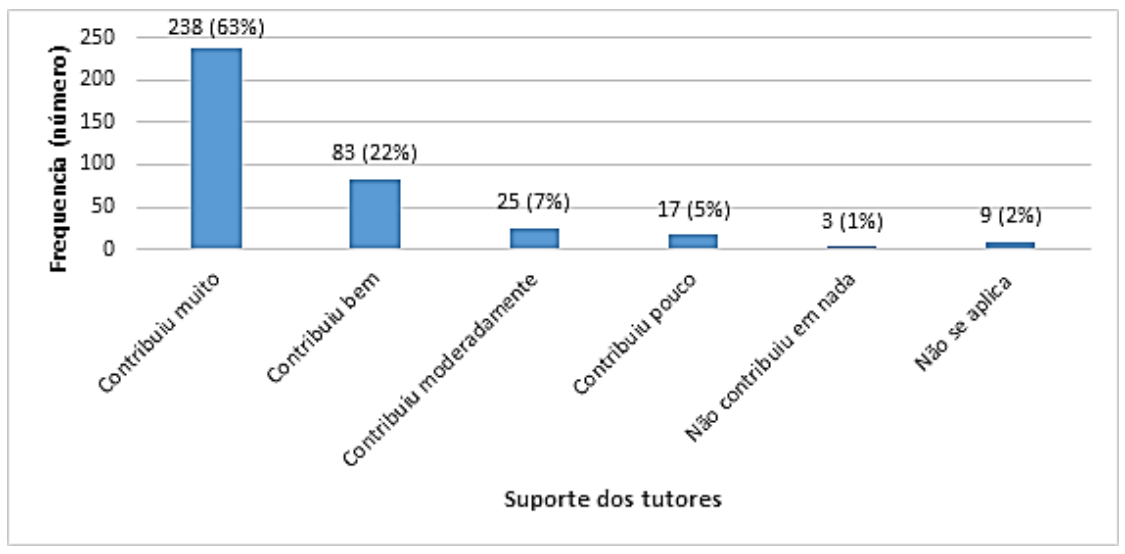

Fonte: Dados da pesquisa, 2014 a 2018.

A maioria dos cursistas, 238 (63\%) afirmaram que o suporte dos tutores contribuiu muito para o seu aprendizado, $83(22 \%)$ afirmaram que contribuiu bem. O que expressa a importância do tutor no processo de ensino-aprendizagem em EAD. Telles e Esquincalha (2017, p. 13) destacam a necessidade da "presença de um orientador, alguém habilitado a observar e ajudar na trajetória para a construção do conhecimento desse aluno". Já Santos e Sato (2016, p.3) salientam que, o foco principal do tutor está na "construção do conhecimento do discente, fazendo com que ele pense e saiba ser crítico, utilizando seu tempo de trabalho no acompanhamento virtual dos educandos, instruindo, mediando, sanando dúvidas, motivando e provocando aprendizagens significativas".

Quanto a percepção dos cursistas em relação ao atendimento, ao esclarecimento de dúvidas e questionamentos ao longo do curso (figura 2), verificou-se que 285 (76\%) dos cursistas concordaram que suas dúvidas e questionamentos foram plenamente atendidos e somente 10 (3\%) discordaram totalmente em relação a esse auxílio do tutor. Salienta-se que, 57 (15\%) dos cursistas optaram pela opção "não se aplica" visto que não necessitaram desse tipo de suporte do tutor ao longo do curso.

Figura 2: Grau de concordância dos cursistas quanto ao esclarecimento de dúvidas e questionamentos pelo tutor, 2015 a 2018.

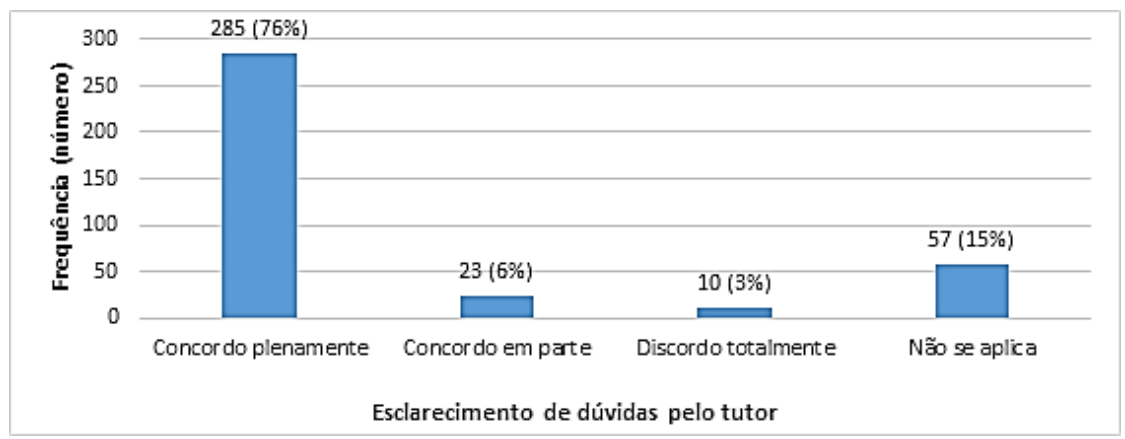


Fonte: Dados da pesquisa, 2015 a 2018.

Segundo Valente (2005) apud Silva e Teixeira da Silva (2009, p. 80), " o aluno deve está engajado na resolução de um problema ou projeto e suas dificuldades ou dúvidas podem ser sanadas com a ajuda do professor [tutor] ou demais membros do grupo". Os autores acrescentam que, "o aluno recebe as ideias do professor [tutor], reflete, tenta colocá-las em ação, o que pode gerar novas dúvidas, as quais poderão ser novamente comunicadas ao professor e aos demais colegas". Daí a importância de haver um tutor para orientar o cursista, afinal, estamos vivenciando um momento de transformações no que tange a prática de ensino, principalmente devido à quebra do paradigma bancário inserção das TICs na educação.

Para verificar se as respostas dadas pelos tutores foram claras e objetivas, sanando com eficiência as dúvidas e questionamentos dos cursistas, verificou-se o grau de concordância em relação a clareza e objetividade das respostas dos tutores, conforme representado na figura 3 :

Figura 3: Grau de concordância dos cursistas em relação a clareza e objetividade dos tutores no esclarecimento de dúvidas e questionamentos, 2015 a 2018.

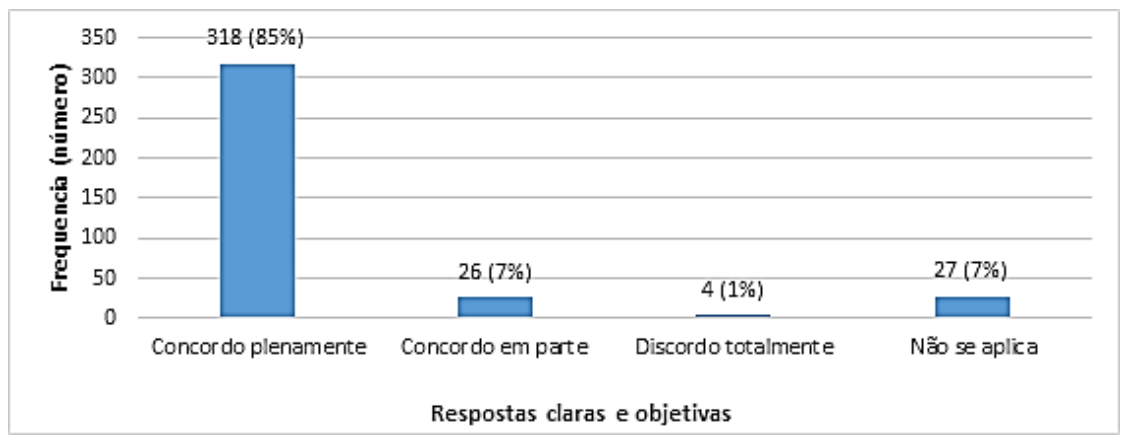

Fonte: Dados da pesquisa, 205 a 2018.

Verificou-se, que 318 (85\%) dos cursistas concordaram plenamente que as respostas dadas as suas dúvidas e questionamentos foram claras e objetivas e apenas 4 (1\%) dos cursistas discordaram totalmente dessa afirmação.

Saber se comunicar de maneira clara e objetiva é um fator essencial no processo de ensino e, principalmente, na tutoria em EAD, haja vista que a comunicação entre tutor e cursista é realizado por meio de recursos de comunicação síncrona ou assíncrona (email, fórum, chat, watsApp, e outros), mas quando não bem utilizadas não alcançam seu potencial de ação e muito menos a compreensão gerada na comunicação presencial. 
Gomes e Villani (s.d., p.13) corroboram com tal afirmação e apontam que, saber se expressar "de maneira clara e concisa em fóruns, chat e e-mails, explicando e dando todos os detalhes possíveis" é uma capacidade fundamental para o exercício da tutoria.

Para constatar se os cursistas viam a importância de se ter um tutor ao longo do curso, foi verificado o grau de concordância a respeito da afirmação: "Minha participação no curso não precisou de tutor". A figura 4 a seguir representa as respostas dos cursistas:

Figura 4: Grau de concordância dos cursistas sobre a necessidade de se ter um tutor durante o curso, 2015 a 2018.

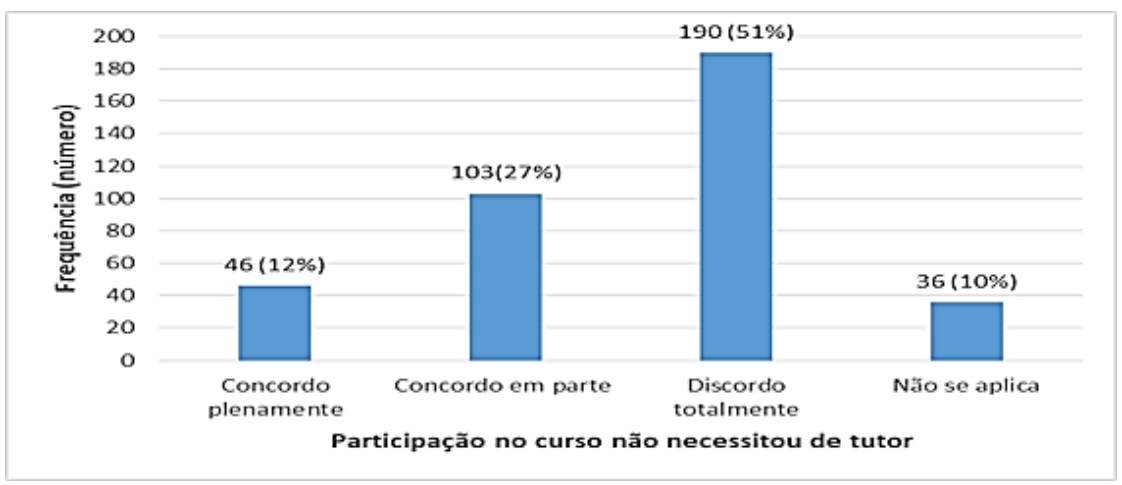

Fonte: Dados da pesquisa, 2015 a 2018.

A maioria dos cursistas, 190 (51\%), afirmaram que a sua participação no curso precisou do tutor, o que, mais uma vez, confirma a importância do tutor na EAD. Para Schemin e Almeida (2017, p.13) "a mediação pedagógica permite ao educador demonstrar ser interessante aos alunos terem acesso à aprendizagem mediante abordagens significativas. $O$ ato de mediar significa ser uma ponte conciliadora entre o conhecimento e o aluno".

Diante disso, os resultados evidenciaram que para os cursistas o exercício da tutoria é fundamental no desenvolvimento de um curso à distância, bem como na permanência até o final do curso.

\section{Considerações finais}

De acordo com os resultados o estudo possibilita reflexões quanto a atuação mais proativa do tutor em cursos a distância. Conforme pôde-se aferir, de forma geral, os cursistas acreditam que ter um tutor à sua disposição para esclarecimento de dúvidas e questionamentos, orientando sobre o andamento do curso e mediando o processo de ensino-aprendizagem é um fator importante no desenvolvimento e aprendizagem em um curso EAD, como também, na permanência e êxito ao longo do curso.

Os resultados desse estudo permitem afirmar que o tutor precisa ter a capacidade de 
manter um diálogo claro e objetivo com o cursista, sendo esse um aspecto motivador para o desempenho e permanência no curso.

Ademais, o que depreende dos resultados desse estudo é que a capacitação de tutores faz-se necessária para que ao exercer a atividade de tutoria, tão relevante no contexto da EAD, o tutor possa refletir sobre o efeito influenciador e motivador da sua atuação de modo a ressignificar o seu papel de educador.

\section{Referências}

BELLONI, M.L. Educação a Distância. 2ª ed. São Paulo: Autores Associados, 2001. $115 p$.

CASTELLS, M. A sociedade em rede. Tradução Roneide V. Majer. 13ª Ed. São Paulo: Paz e Terra, 2010. 698 p.

FREIRE, Paulo. Pedagogia do oprimido. Rio de Janeiro: Paz e Terra 1974. 253 p.

GOMES, S.G.S.; VILLANI, E.A. Formação de Tutores. Curso de Capacitação de Tutores. Viçosa: Coordenadoria de Educação Aberta e a Distância/UFV, s.d., 53 f. Apostila.

MARTINS, J. G. Aprendizagem baseada em problemas aplicada a ambiente virtual de aprendizagem, 291 f. 2002. Tese (Doutorado em Engenharia de Produção). Universidade Federal de Santa Catarina. Florianópolis-SC.

MARTINS, O. B. Teoria e prática tutorial em educação a distância. RevistaEducar, Curitiba, n.21, p. 153-171, 2003.

MELLO, R.M.A.V.; BARBOSA, J.M.S.; SOARES, L.A.; FLORESTA, M.G.S. O programa nacional de formação continuada e a distância de gestores escolares no âmbito de Universidade Federal de Viçosa. In: MELLO, R.M.A.V.; BARBOSA, J.M.S.; FLORESTA, M.G. (Orgs.). Formação de profissionais da educação básica pública: reflexões para se pensar e educação a distância. Curitiba: CRV, 2017. Cap. 2, p. 25-41.

MEIRINHO. M.; OSÓRIO, A. O estudo de caso como estratégia de investigação em educação. EDUSER: Revista de educação. V.2, n.2, 2010. pp. 49-65.

MINAYO, M. C. S; SANCHES, O. Quantitativo-qualitativo: oposição ou complementariedade? Caderno de Saúde Pública, vol. 9, n. 3, Rio de Janeiro, p. 247, 
1993.

MORAN, José Manuel. A educação que desejamos: novos desafios e como chegar lá. $2^{\circ}$ ed. Campinas, SP: Papirus, 2012. 174p.

O'ROURKE, J. Tutoria no EAD: Um manual para tutores. Vancouver, The Commonwealth of Learning, 2003.

SANTOS, J. I.; SATO, M. K. P. As contribuições de Freire para a prática da tutoria em EAD com ênfase no uso do e-mail como ferramenta pedagógica. In: SIED - SIMPÓSIO INTERNACIONAL DE EDUCAÇÃO A DISTÂNCIA E ENPED - ENCONTRO DE PESQUISADORES EM EDUCAÇÃO A DISTÂNCIA, 2016, São Carlos. Anais eletrônicos... São Paulo: UFSCar, 2005. Disponível em: < http://www.siedenped2016.ead.ufscar.br/ojs/index.php/2016/article/view/2110>. Acesso em: 18 mai. 2018.

SILVA, A.C.; TEIXEIRA DA SILVA, C.M. Avaliação de ambientes virtuais de aprendizagem. In: SILVA, A.C. (Org.). Aprendizagem em ambientes virtuais: e educação a distância. Porto Alegre: Mediação, 2008. cap.3, p.73-88.

SCHEMIN, A.C.C.; ALMEIDA, S.C.D. Mediação pedagógica do professor-tutor em cursos na modalidade de educação a distância - EAD. In: ALMEIDA, S.C.D.;MEDEIROS, L.F.M.; MATTAR, J. (Orgs.) Educação e tecnologias: refletindo e transformando o cotidiano. São Paulo: Artesanato Educacional, 2017. cap.1, p.7-30.

TELLES, W. R.; ESQUINCALHA, A. C. O tutor a distância e sua formação para o trabalho em ambientes virtuais. Revista Brasileira de Aprendizagem Aberta e a Distância, v.16, p. $11-21$, set. 2017.

TORI, R. A distância que aproxima. Revista de Educação a Distância, v. 1, n. 2, p. 1-6, 2002. Disponível em: . Acesso em dezembro 2009.

VIEIRA,V. A. As tipologias, variações e características da pesquisa de marketing. Revista FAE, Curitiba, v.5, n.1, p.61-70, jan./abr. 2002. 